\title{
Pengaruh Harga Jual, Pasar, Bahan Baku, dan Modal Usaha terhadap Pendapatan Home Industry Telur Asin di Desa Kebonsari Kecamatan Candi Sidoarjo
}

\author{
*Ade Puspitasari, Juliani Pudjowati, Abdul Fattah \\ Prodi Ekonomi Pembangunan Fakultas Ekonomi dan Bisnis \\ Universitas Bhayangkara Surabaya, Indonesia
}

DOI: $10.46821 /$ bharanomics.v2i1.188

\begin{abstract}
Abstrak
Penelitian ini bertujuan untuk mengetahui "Pengaruh Harga Jual, Pasar, Bahan Baku, dan Modal Usaha baik secara parsial maupun simultan terhadap Pendapatan Home Industry Telur Asin di Desa Kebonsari Kecamatan Candi Sidoarjo”. Sampel penelitian ini adalah Pemilik Home Industry di Desa Kebonsari Kecamatan Candi Sidoarjo. Teknik pengambilan sampel menggunakan teknik sampling jenuh. Pengujian data ini menggunakan Uji Normalitas, Uji Reliabilitas, Uji Validitas, Uji Regresi Berganda, Uji $F$, Uji t, Uji R Square, dan Uji Dominan. Hasil penelitian ini menunjukan bahwa Harga Jual dan Modal Usaha tidak berpengaruh signifikan terhadap Pendapatan Home Industry Telur Asin, Pasar dan Modal Usaha berpengaruh positif signifikan terhadap Pendapatan Home Industry Telur Asin. Variabel yang dominan adalah Pasar.
\end{abstract}

Kata Kunci: Harga Jual, Pasar, Bahan Baku, dan Modal Usaha.

\begin{abstract}
:
This study aims to find out "The influence of Selling Price, Market, Raw Materials, and Business Capital both partially and simultaneously on the Income of Salted Egg Home Industry in Kebonsari Village, Candi Sidoarjo District". The sample of this study is the Owner of Home Industry in Kebonsari Village, Sidoarjo Temple District. Sampling techniques use saturated sampling techniques. This data test uses Normality Test, Reliability Test, Validity Test, Multiple Regression Test, F Test, T Test, R Square Test, and Dominant Test. The results of this study showed that the Selling Price and Business Capital had no significant effect on the Home Industry Revenue of Salted Eggs, Market and Business Capital significantly positively influenced the Home Industry Revenue of Salted Eggs. The dominant variable is the Market.
\end{abstract}

Keywords: Selling Price, Market, Raw Materials, and Business Capital.

\section{PENDAHULUAN}

Desa Kebonsari masuk wilayah kecamatan Candi kabupaten Sidoarjo. Kondisi letak desa sebagian kontur tanahnya adalah datar, persawahan membentang dari arah Utara ke Selatan. Lokasi irigasi kebanyakan dekat disamping persawahan penduduk, sehingga pada saat musim kemarau air menjadi sangat mudah. Penghasilan masyarakat atau warga desa yang tergolong masih rendah dibanding dengan masyarakat atau warga desa lain yang ada di kecamatan Candi. Dari penghasilan lainnya belum ada yang bisa diandalkan, tetapi dengan semangat gotong royong tetap tumbuh dan berkembang dalam setiap kegiatan pembangunan di Desa Kebonsari kecamatan Candi. Untuk meningkatkan penghasilan masyarakat atau warga memanfaatkan keterampilan yang dimiliki secara turun 
temurun dengan membuat telur asin. Dan menjadikan telur asin sebagai usaha rumahan/Home industry (Purwanti, 2017).

Home industry juga merupakan wadah masyarakat yang tumbuh dan berkembang secara mandiri dengan memberikan penghasilan tambahan serta perubahan pada kondisi sosial ekonomi masyarakat dan lingkungan yang ada disana. Pada Home Industry Telur Asindi Kebonsari saat ini memberikan manfaat pada masyarakat. Dan dianggap sebagai cara yang tepat untuk meningkatkan perekonomian masyarakat atau warga setempat (Wibowo, 2018).

Pasar adalah kumpulan dari seluruh permintaan dan penawaran dari barang-barang dan jasa-jasa. Pasar terdiri atas pasar konkrit dan pasar abstrak. Pasar Konkrit adalah tempat dimana berkumpul para pembeli dan penjual untuk memperdagangkan barang-barang. Sedangkan pasar abstrak terjadi apabila barang-barang yang di perdagangkan tidak ada di pasar. Pasar merupakan salah satu faktor terpenting untuk menunjukkan usaha khususnya yang bergerak dalam bidang barang dan jasa (Goenadhi dan Nobaiti, 2017:59).

Modal Usaha adalah modal awal yang nilainya bervariasi tergantung jenis usaha yang dijalankan serta besar kecilnya usaha tersebut saat akan dimulai. Modal merupakan sekumpulan uang atau barang yang digunakan sebagai dasar untuk melaksanakan suatu pekerjaan. Modal merupakan hal yang sangat vital dan penting dalam sebuah bisnis atau usaha. Tanpa modal bisnis tidak akan berjalan sesuai dengan rencana, mulai dari bisnis besar maupun bisnis kecil membutuhkan modal untuk menjalankan bisnisnya (Sudaryono, 2017).

Pemilihan bahan baku dan bahan pakan ternak bebek yang berprotein tinggi membuat rasa telur asin yang dihasilkan memiliki rasa yang khas dan unik. Bahan baku utama usaha ini adalah garam laut dan telur dengan kualitas yang bagus, bahan baku ini dipeloleh dari hasil budidaya bebek sendiri, ada juga yang membeli langsung ke perternak bebek di kalangan masyarakat yang tidak mengawetkan telur asin. Pendapatan juga bisa digunakan sebagai alat untuk mengukur kondisi ekonomi seseorang atau rumah tangga. Pendapatan menunjukkan seluruh uang atau hasil material lainnya yang dicapai dari penggunaan kekayaan atau jasa yang diterima seseorang atau rumah tangga selama jangka waktu tertentu pada suatu kegiatan ekonomi (Firdausa, 2016).

Permasalahan pengusaha telur asin saat ini yaitu pendapatan yang didapatkan saat ini tidak sebanyak dulu, karena orderan yang sepi. Tentu saja berdampak pada pendapatan yang diperoleh dan dipengaruhi kondisi ekonomi saat ini akibat dari pandemi. Sedangkan untuk memasarkan Home industry telur asin tersebut di jual di pasar, toko-toko, warung makan serta bisa juga pembelian secara online.

Harga merupakan suatu nilai produk, karena akan berpengaruh terhadap keuntungan produsen. Harga juga menjadi pertimbangan konsumen untuk membeli, sehingga perlu pertimbangan khusus untuk menentukan harga tersebut. Harga yang dihasilkan dapat berubah-ubah sesuai harga pemasaran dan harga jual produknya. Harga jual merupakan harga pada saat menjual barang atau jasa kepada konsumen (Hasan, 2018).

Tujuan penelitian ini ialah untuk mengetahui dan menganalisis apakah Harga Jual, Pasar, Bahan Baku, dan Modal Usaha berpengaruh secara signifikan terhadap Pendapatan Home Industry Telur Asin di Desa Kebonsari Kecamatan Candi Sidoarjo. Untuk mengetahui dan menganalisis manakah diantara Harga 
Jual, Pasar, Bahan Baku, dan Modal Usaha yang berpengaruh dominan terhadap Pendapatan Home Industry Telur Asin di Desa Kebonsari Kecamatan Candi Sidoarjo.

Berdasarkan latar belakang di atas, peneliti tertarik untuk melakukan penelitian tentang "PENGARUH HARGA JUAL, PASAR, BAHAN BAKU, DAN MODAL USAHA TERHADAP PENDAPATAN HOME INDUSTRY TELUR ASIN DI DESA KEBONSARI KECAMATAN CANDI SIDOARJO".

\section{TINJAUAN PUSTAKA}

\section{Pendapatan}

Pendapatan menunjukkan jumlah uang yang diterima oleh rumah tangga selama kurun waktu tertentu (biasanya satu tahun), Pendapatan terdiri dari upah atau peneriman tenaga kerja, pendapatan dari kekayaan seperti sewa, bunga dan deviden, serta pembayaran transfer atau penerimaan dari pemerintah seperti tnjangan sosial atau asuransi pengangguran (Samuelson \& Nordhaus, 2015).

\section{Harga Jual}

Harga adalah elemen bauran penjualan yang dapat menghasilkan pendapatan melalui penjualan produk. Proses pembentukan harga dipengaruhi oleh interaksi antara penawaran dan permintaan akan sesuatu barang dan jasa di dalam suatu pasar. Harga jual merupakan harga pada saat menjual barang atau jasa kepada konsumen (Hasan, 2018).

\section{Pasar}

Pasar adalah kumpulan dari seluruh permintaan (pembeli) dan penawaran (penjual) dari barang-barang dan jasa-jasa. Menurut bentuk fisiknya, pasar terdiri atas pasar konkret daan pasar abstrak. Pasar konkret adalah tempat dimana berkumpul para pembeli dan penjual untuk memperdagangkan barang-barang. Sedangkan pasar abstrak terjadi apabila barang-barang yang diperdagangkan tidak ada di pasar (Goenadhi \& Nobaiti, 2017).

\section{Bahan Baku}

Bertambahnya jumlah bahan baku yang digunakan maka akan meningkatkan hasil produksi. Bahan baku langsung atau direct material adalah semua bahan baku yang merupakan bagian dari barang jadi yang dihasilkan. Bahan baku tidak langsung atau indirect material adalah bahan baku yang ikut berperan dalam proses produksi tetapi tidak secara langsung tampak pada barang jadi yang dihasilkan (Adisaputro, 2016).

\section{Modal Usaha}

Modal dapat diartikan sebagai sejumlah uang yang digunakan dalam menjalankan kegiatan-kegiatan bisnis. Banyak kalangan yang memandang bahwa modal uang bukan segala-galanya dalam sebuah bisnis. Namun perlu dipahami bahwa uang dalam sebuah usaha sangat diperlukan. Yang menjadi persoalan disini bukanlah penting tidaknya modal, karena keberadaannya memang sangat diperlukan, akan tetapi bagaimana mengelola modal secara optimal sehingga bisnis yang dijalankan dapat berjalan lancar (Amirullah, 2015). 


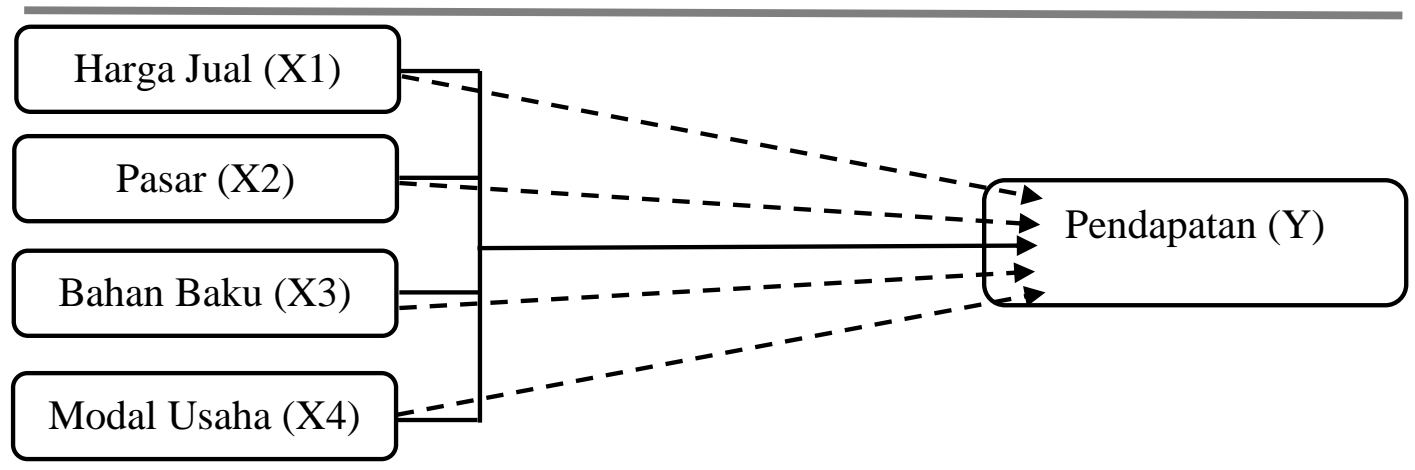

Gambar 1

Kerangka Konseptual

Keterangan :

$\longrightarrow \quad$ : Pengaruh Secaara Simultan $X_{1}, X_{2}, X_{3}$, dan $Y$

$---\rightarrow$ : Pengaruh Secaara Parsial $X_{1}, X_{2}, X_{3}$, dan

\section{Hipotesis Penelitian}

1. Bahwa variabel Harga Jual berpengaruh signifikan terhadap pendapatan Home Industry di Desa Kebonsari Kecamatan Candi Kabupaten Sidoarjo.

2. Bahwa variabel Pasar berpengaruh signifikan terhadap pendapatan Home Industry di Desa Kebonsari Kecamatan Candi Kabupaten Sidoarjo.

3. Bahwa variabel Bahan Baku berpengaruh signifikan terhadap pendapatan Home Industry di Desa Kebonsari Kecamatan Candi Kabupaten Sidoarjo.

4. Bahwa variabel Modal Usaha berpengaruh signifikan terhadap pendapatan Home Industry di Desa Kebonsari Kecamatan Candi Kabupaten Sidoarjo.

5. Bahwa variabel Harga Jual berpengaruh dominan terhadap pendapatan Home Industry di Desa Kebonsari Kecamatan Candi Kabupaten Sidoarjo.

\section{METODE PENELITIAN}

\section{Populasi}

Populasi adalah wilayah generalisasi yang terdiri atas objek atau subjek yang mempunyai kualitas dan ciri tertentu yang ditetapkan oleh peneliti untuk dipelajari dan kemudian ditarik kesimpulannya (Sugiyono, 2017). Populasi yang digunakan dalam penelitian ini adalah Pengusaha Telur Asin yang berada di Desa Kebonsari Kabupaten Candi Kota Sidoarjo.

\section{Sampel}

Sampel adalah bagian dari jumlah dan karakteristik yang dimiliki oleh populasi tersebut bila populasi besar dan peneliti tidak mungkin mempelajari semua yang ada pada populasi, misal karena keterbatasan dana, tenaga dan waktu, maka peneliti dapat menggunakan sampel yang diambil dari populasi itu. Untuk itu sampel yang diambil dari populasi harus betul-betul representatif (mewakili) (Sugiyono, 2017)

\section{HASIL DAN PEMBAHASAN}

Uji Normalitas

Uji Normalitas data dilakukan untuk mengetahui apakah data yang diteliti dalam penelitian ini terdistribusikan normal atau tidak. Untuk menguji normalitas dalam 
penelitian ini menggunakan One Sample Solgomorov Sminov Test. Dasar pengambilan keputusan adalah jika Sig (2-tailed) > 0,05, maka model regresi memenuhi asumsi normalitas dan sebaliknya (Ghozali, 2018:161).

Berdasarkan hasil perhitungan tabel 1 dikethui bahwa nilai Sig (2-tailed) $>0,05$ maka data berdistribusi normal. Maka dapat dilihat dari tabel nilai Sig (2tailed) sebesar 0,244>0,05 yang berarti nilainya sama maka data penelitian ini berdistribusi normal.

\section{Uji Reliabilitas}

Uji Reliabilitas data dilakukan untuk mengetahui apakah data yang diteliti dalam penelitian ini menggunakan Koefisien Cronbach's Alpha. Suatu konstruk variabel dikatakan reliabel jika memiliki nilai Cronbach's Alpha > 0,60 (moderat). Jika nilai alpha $>0,70$ artinya reliabilitas mencukupi (sufficient reliability), sementara jika alpha $>0,80$ ini menunjukkan seluruh item relibel dan seluruh tes secara konsisten dan secara nternalmemiliki reliabilitas yang kuat. Jika alpha rendah dengan alpha $<0,50$,kemungkinan satu atau beberapa item tidak reliabel.

Tabel 1

Hasil Uji Normalitas One-Sample Kolmogorov-Smirnov Test

\begin{tabular}{lll}
\hline & & Unstandardized Residual \\
\hline $\mathrm{N}$ & & 50 \\
Normal Parameters $^{\mathrm{a}, \mathrm{b}}$ & Mean & .0000000 \\
& Std. Deviation & 1.18736710 \\
Most Extreme Differences & Absolute & .145 \\
& Positive & .093 \\
& Negative & -.145 \\
Test Statistic & & .145 \\
Asymp. Sig. (2-tailed) & & $.244^{\mathrm{c}}$ \\
\hline
\end{tabular}

a. Test distribution is Normal.

b. Calculated from data.

c. Lilliefors Significance Correction.

Sumber: Data Diolah (2021)

Tabel 2

Hasil Uji Reliabilitas

\begin{tabular}{lcccc}
\hline Variabel & $\begin{array}{c}\text { Cronbach's } \\
\text { Alpha }\end{array}$ & Tanda & $\begin{array}{c}\text { Minimal Cronbach's } \\
\text { Alpha }\end{array}$ & Keterangan \\
\hline Harga Jual (X1) & 0,766 & $>$ & 0,60 & Reliabel \\
Pasar (X2) & 0,851 & $>$ & 0,60 & Reliabel \\
Bahan Baku (X3) & 0,687 & $>$ & 0,60 & Reliabel \\
Modal Usaha (X4) & 0,850 & $>$ & 0,60 & Reliabel \\
Pendapatan (Y) & 0,723 & $>$ & 0,60 & Reliabel \\
\hline
\end{tabular}

Sumber: Data Diolah (2021) 


\section{Tabel 3}

\section{Uji Analisis Regresi Linier Berganda}

\begin{tabular}{|c|c|c|c|c|c|c|c|c|}
\hline \multicolumn{9}{|c|}{ Coefficients $^{\mathrm{a}}$} \\
\hline \multirow[b]{2}{*}{ Model } & \multicolumn{2}{|c|}{$\begin{array}{c}\text { Unstandardized } \\
\text { Coefficients }\end{array}$} & \multirow{2}{*}{$\begin{array}{c}\text { Standardized } \\
\text { Coefficients } \\
\text { Beta }\end{array}$} & \multirow[b]{2}{*}{$\mathrm{t}$} & \multirow[b]{2}{*}{ Sig. } & \multicolumn{3}{|c|}{ Correlations } \\
\hline & B & Std. Error & & & & $\begin{array}{l}\text { Zero- } \\
\text { order }\end{array}$ & Partial & Part \\
\hline 1 (Constant) & 11.311 & 4.059 & & 2.787 & .008 & & & \\
\hline $\begin{array}{l}\text { HARGA JUAL } \\
(\mathrm{X} 1)\end{array}$ & -.059 & .121 & -.070 & -.488 & .628 & .018 & -.073 & $\begin{array}{c}- \\
.066\end{array}$ \\
\hline PASAR (X2) & .198 & .134 & .217 & 1.481 & 146 & .246 & .216 & .200 \\
\hline $\begin{array}{l}\text { BAHAN } \\
\text { BAKU (X3) }\end{array}$ & -.256 & .135 & -.278 & -1.902 & .064 & -.142 & -.273 &. \\
\hline $\begin{array}{l}\text { MODAL } \\
\text { USAHA (X4) }\end{array}$ & .192 & .093 & .303 & 2.075 & .044 & .293 & .295 & .280 \\
\hline
\end{tabular}

a. Dependent Variable: PENDAPATAN (Y)

Sumber: Data Diolah (2021)

\section{Uji Validitas}

Uji validitas digunakan untuk mengukur valid atau tidaknya item pada kuisoner. Pengujian validitas dilakukan berdasarkan analisis item yaitu mengkorelasi skor setiap item dengan skor variabel (hasil penjumlahan seluruh skor item pernyataan). Teknik korelasinya memakai Pearson Correlation, dihitung dengan menggunakan bantuan computer program SPSS. Item pernyataan dinyatakan valid apabila memiliki nilai probabilitas tingkat signifikansi $<5 \%(0,05)$ (Sugiyono, 2017).Dapat dilihat $\mathrm{df}=\mathrm{n}-2$ maka besarnya $\mathrm{df}=50-2=48$ dengan alpha $5 \%(\alpha=0,05)$, dapat dilihat $r_{\text {tabel }}=0,2787$.

\section{Uji Analisis Regresi Linear Berganda}

Teknik analisis ini digunakan untuk menetahui variabel independent (bebas) yaitu, Harga Jual, Pasar, Bahan Baku, dan Modal Usaha berpengaruh terhadap variabel dependen (terikat) yaitu, Pendapan Home Industry Telur Asin dengan menggunakan persamaan regresi program SPSS 25.0 for windows.

Berdasarkan tabel 2, maka diperoleh persamaan regresi linear berganda sebagai berikut :

$$
\begin{aligned}
& \mathrm{Y}=\mathrm{a}+\mathrm{b}_{1} \mathrm{X}_{1}+\mathrm{b}_{2} \mathrm{X}_{2}+\mathrm{b}_{3} \mathrm{X}_{3}+\mathrm{b}_{4} \mathrm{X}_{4}+\mathrm{e} \\
& \mathrm{Y}=11,311+-0,59 \mathrm{X}_{1}+0,198 \mathrm{X}_{2}+-0,256 \mathrm{X}_{3}+0,192 \mathrm{X}_{4}+\mathrm{e} \\
& \text { Keterangan : } \\
& \mathrm{Y} \quad=\text { Pendapatan Home Industry Telur Asin } \\
& \mathrm{a} \quad=\text { Konstanta } \\
& \mathrm{X}_{1} \quad=\text { Harga Jual } \\
& \mathrm{X}_{2} \quad=\text { Pasar } \\
& \mathrm{X}_{3} \quad=\text { Bahan Baku } \\
& \mathrm{X}_{4} \quad=\text { Modal Usaha } \\
& \mathrm{e} \quad=\text { error } \\
& \mathrm{b}_{1}, \mathrm{~b}_{2}, \mathrm{~b}_{3}, \mathrm{~b}_{4}=\text { Koefisien Regresi }
\end{aligned}
$$




\begin{tabular}{|c|c|c|c|c|c|c|}
\hline \multicolumn{7}{|c|}{$\begin{array}{c}\text { Tabel } 4 \\
\underset{\text { Hasil Uji Simultan }}{\text { Siji F) }} \\
\text { ANOVA }^{\mathrm{a}} \\
\end{array}$} \\
\hline Model & & Sum of Squares & df & Mean Square & $\mathrm{F}$ & Sig. \\
\hline \multirow[t]{3}{*}{1} & Regression & 13.830 & 4 & 3.457 & 2.864 & $.000^{\mathrm{b}}$ \\
\hline & Residual & 63.050 & 45 & 1.401 & & \\
\hline & Total & 76.880 & 49 & & & \\
\hline
\end{tabular}

a. Dependent Variable: PENDAPATAN (Y)

b. Predictors: (Constant), MODAL USAHA (X4), HARGA JUAL (X1), BAHAN BAKU (X3), PASAR (X2)

Sumber: Data Diolah (2021)

Dari persamaan regresi linier berganda diatas dapat diliihat besarnya pengaruh variabel independent $\left(\mathrm{X}_{1}, \mathrm{X}_{2}, \mathrm{X}_{3}, \mathrm{X}_{4}\right)$ terhadap variabel dependen $(\mathrm{Y})$, sehingga diketahui diantara ketiga variabel tersebut variabel mana yang mempunyai pengaruh paling besar.

\section{Uji Simultan (Uji F)}

Uji $\mathrm{F}$ bertujuan untuk mengetahui apakah variabel independent (bebas) secara bersama-sama berpengaruh terhadap variabel dependen (terikat). Pengujian ini dilakukkan dengan membandingkan nilai signifikan $\mathrm{F}$ hitung dengan taraf signifikan yang digunakan sebesar 0,05 (5\%) (Ghozali, 2016:96).

Pada tabel 4, hasil pengujian dengan program SPSS 25.0 for windows dapat diperoleh hasil bahwa nilai $F_{\text {hitung }}$ sebesar 2,864 dan nilai $F_{\text {tabel }}$ sebesar 2,58 dengan nilai probabilitas $(\mathrm{sig})=0,000$. Sehingga diketahui bahwa $F_{\text {hitung }} 2,864<$ $\mathrm{F}_{\text {tabel }} 2,58$ dan nilai sig lebih kecil dari nilai probabilitas 0,05 atau nilai 0,000 . Sesuai dengan langkah-langkah pengujian maka H0 ditolak dan $\mathrm{H} 1$ diterima. Dapat diumpulkan bahwa secara simultan antara variabel independen Harga Jual (X1), Pasar (X2), Bahan Baku (X3), dan Modal Usaha (X4) berpengaruh terhadap Pendapatan Home Industry Telur Asin di Desa Kebonsari (Y).

\section{Uji Parsial (Uji t)}

Uji t dilakukan utuk menguji pengaruh variabel bebas terhadap variabel terikat. Uji $t$ dilakukkan dengan membandingkan $t_{\text {hitung }}$ dengan $t_{t a b e l}$. Dari hasil pengujian dengan program SPSS 25.0 for windows, dapat dilihat pada tabel 5.

Pada tabel 5 diatas berdasarkan perhitungan SPSS menunjukkan bahwa Uji t dalam penelitian ini menggunakan taraf signifikansi 5\% atau 0,05 dengan pengujian dua sisi dan df (n-k) maka diperoleh $\mathrm{t}_{\text {tabel }}=2,01290$.

Maka dapat dijelaskan sebagai berikut :

$\mathrm{X}_{1}$ : $\mathrm{t}_{\text {hitung }}(-0,488)>\mathrm{t}_{\text {tabel }}(2,01290)=\mathrm{H}_{0}$ diterima $\mathrm{H}_{1}$ ditolak.

$\mathrm{X}_{2}: \mathrm{t}_{\text {hitung }}(2,481)>\mathrm{t}_{\text {tabel }}(2,01290)=\mathrm{H}_{0}$ ditolak $\mathrm{H}_{1}$ diterima.

$\mathrm{X}_{3}: \mathrm{t}_{\text {hitung }}(-1,902)>\mathrm{t}_{\text {tabel }}(2,01290)=\mathrm{H}_{0}$ diterima $\mathrm{H}_{1}$ ditolak.

$\mathrm{X}_{4}: \mathrm{t}_{\text {hitung }}(2,075)>\mathrm{t}_{\text {tabel }}(2,01290)=\mathrm{H}_{0}$ ditolak $\mathrm{H}_{1}$ diterima.

\section{Uji Koefisien Determinasi atau R Square $\left(\mathbf{R}^{\mathbf{2}}\right)$}

Menurut Ghozali (2016:95) mengatakan bahwa "Koefisien determinasi merupakan cara mengukur seberapa jauh kemampuan model Dalam menerangkan variabel- variabel terikat". Koefisien determinasi $\left(\mathrm{R}^{2}\right)$ adalah antara nol sampai satu $(0 \leq \mathrm{R} \leq 1)$. Nilai $\mathrm{R}^{2}$ yang kecil berarti terikat sangat terbatas. Angka 
koefisien determinasi $\left(\mathrm{R}^{2}\right)$ diperoleh dari pengelohan melalui program SPSS yang dapat dilihat pada tabel model summary kolom $\mathrm{R}$ square dapat dilihat pada tabel 6.

Pada tabel 6, dapat dilihat bahwa nilai $\mathrm{R}$ Square $=0,180$ artinya variabel bebas (Harga Jual, Pasar, Bahan Baku, Dan Modal Usaha) secara keseluruhan memberikan pengaruh secara bersama-sama sebesar 18\% terhadap variabel terikat (pendapatan) dan sisanya $100 \%-18 \%=82 \%$ dijelaskan oleh variabel lain atau factor-faktor lain yang tidak termasuk dalam model konseptual untuk dianalisis atau tidak ikut diteliti.

\section{Variabel Dominan}

Variabel Dominan merupakan uji yang digunakan untuk mengetahui variabel mana yang dominan pengaruhnya diantara variabel dependen (bebas) yang terdiri dari Harga Jual (X1), Pasar (X2), Bahan Baku (X3), dan Modal Usaha (X4) yang memiliki pengaruh dominan terhadap Pendapatan Home Industry Telur Asin di Desa Kebonsari (Y) dilihat dari nilai koefisien Beta yang tertinggi dari setiap variabel. Dapat dilihat pada $(\beta)$ dari regresi Standardized Coefficients dari masing-masing variabel bebas yang signifikan, variabel yang memiliki koefisien $(\beta)$ beta terbesar merupakan variabel yang dominan.

Pada tabel 7, dapat dilihat bahwa dari keempat varibel bebas yang terdiri dari Harga Jual (X1), Pasar (X2), Bahan Baku (X3), dan Modal Usaha (X4) terdapat satu variabel yang memiliki nilai $(\beta)$ Unstandardized Coefficients yaitu variabel Pasar (X2) dengan nilai $(\beta)$ Beta 0,198. Dapat disimpulkan bahwa variabel Pasar (X2) memiliki nilai paling dominan terhadap Pendapatan Home Industry Telur Asin di Desa Kebonsari (Y).

Tabel 5

\section{Hasil Uji Parsial (Uji t)} Coefficients $^{\mathrm{a}}$

\begin{tabular}{|c|c|c|c|c|c|c|c|c|}
\hline \multirow[b]{2}{*}{ Model } & \multicolumn{2}{|c|}{$\begin{array}{l}\text { Unstandardized } \\
\text { Coefficients }\end{array}$} & \multirow{2}{*}{$\begin{array}{c}\text { Standardized } \\
\text { Coefficients } \\
\text { Beta }\end{array}$} & \multirow[b]{2}{*}{$\mathrm{t}$} & \multirow[b]{2}{*}{ Sig. } & \multicolumn{3}{|c|}{ Correlations } \\
\hline & B & Std. Error & & & & $\begin{array}{l}\text { Zero- } \\
\text { order }\end{array}$ & Partial & Part \\
\hline 1 (Constant) & 11.311 & 4.059 & & 2.787 & .008 & & & \\
\hline $\begin{array}{l}\text { HARGA JUAL } \\
\text { (X1) }\end{array}$ & -.059 & .121 & -.070 & -.488 & .628 & .018 & -.073 & .066 \\
\hline PASAR (X2) & .198 & .134 & .217 & 2.481 & .004 & .246 & .216 & .200 \\
\hline $\begin{array}{l}\text { BAHAN BAKU } \\
\text { (X3) }\end{array}$ & -.256 & .135 & -.278 & -1.902 & .064 & -.142 & -.273 & .257 \\
\hline $\begin{array}{l}\text { MODAL USAHA } \\
\text { (X4) }\end{array}$ & .192 & .093 & .303 & 2.075 & .002 & .293 & .295 & .280 \\
\hline
\end{tabular}

a. Dependent Variable: PENDAPATAN (Y)

Sumber : Peneliti (2021) 


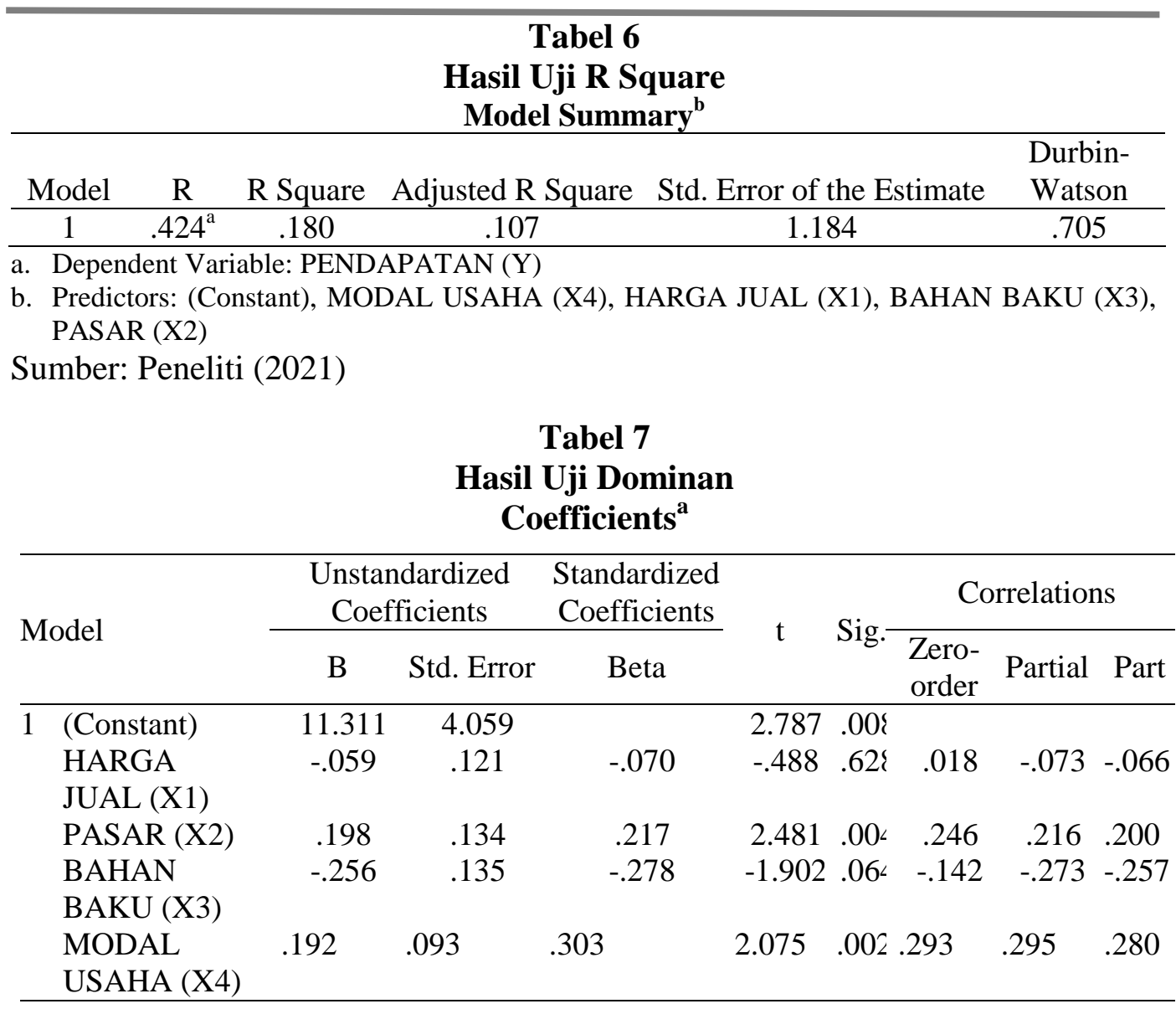

a. Dependent Variable: PENDAPATAN (Y)

Sumber: Hasil data yang diolah peneliti (2021)

\section{SIMPULAN}

Berdasrkan hasil penelitian dan pembahasan mengenai Faktor-aktor yang mempengaruhi Pendapatan Home Industry Telur asin di Desa Kebonsari dapat diambil kesimpulan sebagai berikut, Terbukti bahwa hasil penelitian variabel Harga Jual berpengaruh secara signifikan terhadap variabel Pendapatan Home Industry di Desa Kebonsari. Terbukti bahwa hasil penelitian variabel Pasar berpengaruh secara signifikan terhadap variabel Pendapatan Home Industry di Desa Kebonsari. Terbukti bahwa hasil penelitian variabel Bahan Baku berpengaruh secara signifikan terhadap variabel Pendapatan Home Industry di Desa Kebonsari. Terbukti bahwa hasil penelitian variabel Modal Usaha berpengaruh secara signifikan terhadap variabel Pendapatan Home Industry di Desa Kebonsari. Berdasarkan hasil dari analisis data, hasil pembahasan, dan kesimpulan yang telah di paparkan, maka saran yang bisa diberikan bagi Home Industry Telur asin dan bagi peneliti selanjutnya, sebagai berikut. Bagi Pengusaha Telur asin di Desa Kebonsari diharapkan, a) agar Harga Jual bisa bersaing dengan penjual lain namun harga yang diberikan mampu dijangkau konsumen. Pembelian dengan jumlah banyak akan mendapatkan potogan harga atau harga yang relatif lebih murah daripada Harga Jual secara ecer. b) Pada Pasar diharapkan dapat mengembangkan produk telur asin tidak hanya di Desa Kebonsari tapi di Desa lain. c) Bahan Baku diambil di Desa Kebonsari itu sendiri 
karena agar lebih efisien dan tidak membutuhkan biaya tambahan. d) Modal Usaha harusnya di dukung pemerintah agar Home Industry lebih maju dan lebih banyak yang menjadi pengusaha telur asin untuk menambah pendapatan desa maupun kebutuhan sehari-hari. Penjualan yang menurun karena efek pandemi ini diharapkan bisa meningkatkan pendapatan penjualan dengan cara promosi atau penjualan online lewat instagram, facebook, dan media social lainnya. Untuk peneliti selanjutnya terkait faktor-faktor yang mempengaruhi Pendapatan Home Industry di Desa Kebonsari bisa melanjutkan penelitian dengan menambah variabel atau mengganti dengan variabel lain. Peneliti selanjutnya bisa mengembangkan penelitian ini membuat refrensi baru serta menambah lebih banyak responden dalam penelitian yang dapat mempenharuhi pendapatan pada Home Industry Telur asin di Desa Kebonsari.

\section{DAFTAR PUSTAKA}

Adisaputro. (2016). Anggaran Perusahaan. Yogyakarta. BPFE. Diakses 5 Febuari 2021.

Amirullah. (2015). Pengantar Manajemen. Jakarta: Mitra Wacana Media. Diakses 5 Febuari 2021.

Firdausa, Rosetyadi Artistyan. (2016). Pengaruh Modal Awal, Lama Usaha, Dan Jam Operasional Terhadap Pendapatan Pedagang Kios Di Pasar Bintoro Demak. Diponegoro Journal Of Economics. Vol. 2, No. 1, pp: 1-6. Diakses 10 Januari 2021.

Ghozali, Imam. (2016). Statistik Nonparametrik. Semarang: Badan Penerbit UNDIP. Diakses 3 Maret 2021.

Ghozali, Imam. (2018). Aplikasi Analisis Multivariate Dengan Program IBM SPSS 25 (Badan Penerbit Universitas Diponegoro (ed.); Ke 9) Diakses 10 Maret 2021.

Goenadhi \& Nobaiti. (2017). Pengantar Ekonomi Mikro. Scipta Cendekia. Diakses 3 Maret 2021.

Hasan. (2018). Pengantar Ekonomi: Teori Dan Aplikasi. CV. Nur Lina.Diakses 7 Maret 2021. Diakses 8 Maret 2021.

Purwanti. (2017). Model Pemberdayaan Masyarakat Di "Kampung Bebek Dan Telur Asin" Desa Kebonsari Kecamatan Candi Kabupaten Sidoarjo. Publika, 3(2), 1-15. Retrieved from. Diakses 26 Febuari 2021.

Samuelson dan Nordhaus.2015. Ilmu Makro Ekonomi,Edisi 17 (terjemahan). Jakarta: Media Global Edukasi. Diakses 16 Febuari 2021.

Sudaryono. (2016). Manajemen Pemasaran Teori Dan Implementasi. Yogyakarta: ANDI. Diakses 10 Maret 2021. 
Sugiyono. (2017). Metode Penelitian Pendidikan Pendekatan Kuantitatif, Kualitatif, Dan R\&D. Alfabeta. Diakses 10 Maret 2021.

Wibowo, P. A. (2018). Analisis Faktor-Faktor Yang Mempengaruhi Tingkat Keberhasilan Usaha (Studi Pada Warung "Nasi Kucing" Di Kabupaten Jepara). Jurnal Dinamika Ekonomi \& Bisnis, 5(2), 111-132. Diakses 15 Febuari 2021. 